\title{
Risk-Cost Optimized Maintenance Strategy for Steel Bridge Subjected to Deterioration
}

\author{
Le Li $^{1, *}$, Mojtaba Mahmoodian ${ }^{2}$, Alireza Khaloo ${ }^{3}$ and Zhiyan Sun ${ }^{4}$ \\ 1 College of Engineering and Science, Victoria University, Footscray 3011, Australia \\ 2 School of Engineering, RMIT University, Melbourne 3000, Australia; mojtaba.mahmoodian@rmit.edu.au \\ 3 Department of Civil Engineering, Sharif University of Technology, Azadi Av., Tehran 1458889694, Iran; \\ khaloo@sharif.edu \\ 4 Department of Infrastructure Engineering, The University of Melbourne, Parkville 3010, Australia; \\ zhiyans@student.unimelb.edu.au \\ * Correspondence: li.li1@vu.edu.au
}

check for updates

Citation: Li, L.; Mahmoodian, M.;

Khaloo, A.; Sun, Z. Risk-Cost

Optimized Maintenance Strategy for

Steel Bridge Subjected to

Deterioration. Sustainability 2022, 14,

436. https://doi.org/10.3390/

su14010436

Academic Editor: Maged A. Youssef

Received: 28 November 2021

Accepted: 28 December 2021

Published: 31 December 2021

Publisher's Note: MDPI stays neutral with regard to jurisdictional claims in published maps and institutional affiliations.

Copyright: (c) 2021 by the authors. Licensee MDPI, Basel, Switzerland. This article is an open access article distributed under the terms and conditions of the Creative Commons Attribution (CC BY) license (https:// creativecommons.org/licenses/by/ $4.0 /)$.

\begin{abstract}
This paper aims to develop a deteriorated bridge maintenance strategy that ensures the safe operation of steel structures and minimizes the total risk. Five common failure modes are considered for the deteriorated bridge: flexure, shear, deflection, fatigue failure for girder, and chloride attack for the concrete deck. Time-dependent and system reliability analyses are carried out to find the probability of failure under these failure modes. Risk-cost optimization is then used to determine the maintenance strategy. This method was applied to a working example. It was found that the developed maintenance strategy can predict when, where, and what to maintain for a bridge to ensure its safe and serviceable operation during its lifespan. The proposed methodology can help structural engineers and asset managers repair and maintain bridges under deterioration.
\end{abstract}

Keywords: bridge; deterioration; reliability; risk-cost optimization

\section{Introduction}

Bridges are critical infrastructures that play an important role in transport systems, and the deterioration of bridges has become a global issue [1]. Deterioration is the change to the mechanical properties or the geometric properties of bridge components that affect the bridge's structural performance. There are many causes of deterioration, including corrosion, fatigue, overloading, etc. [2]. Deterioration can lead to capacity loss, remaining life reduction, and bridge failure [1,3]. Biezma and Schanack [4] pointed out that $5 \%$ of bridges have collapsed worldwide from 1807 to 2007 because of deterioration and lack of maintenance, for example, the Silver Bridge in 1967 [5], Lowe's Motor Speedway in 2000 [6], and the Minneapolis Interstate 35 W Bridge in 2007 [7]. These failures indicate that an effective maintenance strategy is essential for a deteriorated bridge to avoid catastrophic failure.

To make maintenance strategy effective, it is essential to minimize the total inspection, repair, and expected failure cost and limit the probability of failure of bridges. Different studies have been carried out to develop the maintenance strategy for bridges, using either the deterministic method or reliability theory. For the deterministic method, Yanev and Chen [8] and Mohammadi et al. [9] used condition rating and the rating deterioration model for life cycle performance prediction and maintenance of bridges. AI-Subhi et al. [10] and Tam and Stiemer [11] developed a bridge maintenance strategy through the life cycle cost analysis and discounted cash flow method. Frangopol [12] incorporated reliability theory and life cycle cost in bridge maintenance. Estes and Frangopol [13], Yang and Hsu [14] and Zhu and Frangopol [15] further developed a maintenance strategy through risk-cost optimization. In this optimization, the deterioration of the bridge is modeled as a stochastic process. Time-dependent reliability theory is used to predict the probability of failure of the 
bridge. An optimization algorithm is then applied to determine the maintenance strategies that ensure the safe operation of the bridge and minimize the total risk [16]. Risk-cost optimization considers the uncertainties in bridge deterioration (e.g., corrosion rate, fatigue damage). Therefore, it can give a more reliable maintenance strategy compared with the deterministic method [17].

Although risk-cost optimization has been used for maintenance strategy development of deteriorated bridges, there are three major research gaps. Firstly, a bridge contains many components (e.g., girder, decks, etc.), and each component has multiple failure modes (e.g., flexure, deflection, and fatigue) [2]. However, most studies only consider the failure of a single component in the risk-cost optimization of bridges. Moreover, Li [2] suggested that bridges can be more vulnerable to fatigue failure than other failure modes. Very limited studies have considered fatigue failure mode in the risk-cost optimization. For example, Stewart and Rosowsky [18], Itoh and Liu [19], and Lounis [20] considered the failure modes (e.g., chloride penetration) only for bridge decks in their risk-cost optimization. The failure modes of other components (e.g., fatigue failure of the bridge girder) have not been considered. Saydam and Frangopol [21] and Liu et al. [22] considered the girders' flexure, shear, and deflection failure modes in the risk-cost optimization. Fatigue failure of girders and the failure modes of decks have not been studied. Based on the system reliability theory, the bridge's probability of failure can be underestimated if any failure modes are not considered. This underestimation can lead to the inefficiency of the developed maintenance strategy [17].

Secondly, corrosion is a common cause of deterioration for steel components (e.g., girder) of the bridge. Corrosion can degrade both sectional properties (e.g., area, effective section modulus, etc.) and mechanical properties (e.g., yield strength, S-N curve, etc.). It is thus vital to consider both degradation impacts in risk-cost optimization of the deteriorated bridge [23]. Most existing works have only considered the corrosion-induced changes in sectional properties, as the cases in Kurtz et al. [24], Guo et al. [25], and Han et al. [26]. Nonetheless, Garbatov et al. [27] suggested that there can be a 20.9\% loss in yield strength of the steel corroded in seawater conditions with a $60 \%$ reduction in weight loss. Li et al. [23] tested the mechanical properties of corroded steel and the results suggested that there can be a $6.1 \%$ loss in yield strength when corrosion loss increases to $1.36 \mathrm{~mm}$. Furthermore, $\mathrm{Li}$ and Mahmoodian [28] suggested that ignoring the reduction in fatigue strength of steel due to corrosion can result in a 57.5 times probability of underestimation of failure. This underestimation indicates that the degradation in mechanical properties of corroded steel should not be ignored in risk-cost optimization and maintenance strategy development.

Thirdly, few studies have used the first passage probability in failure prediction and risk-cost optimization of deteriorated bridges. In detail, bridge deterioration, whatever the causes, is a time-by-time process of accumulation. The autocorrelation of deterioration at each point of time is high $[28,29]$. To consider this autocorrelation, the first passage probability theory can be used for the failure prediction of deteriorated bridges [29] and the subsequent risk-cost optimization works. Mathematically, first passage probability theory determines the probability of failure of each failure mode by estimating the mean outcrossing rate (up- or down-crossing rate) of a stochastic process (e.g., flexure moment, shear force, deflection, fatigue damage, and chloride concentration) from a threshold and obtaining a solution to the so-called "first passage probability" [17]. In calculating the mean outcrossing rate, the autocorrelation of stochastic processes within time is determined [17]. Recent studies have used the first passage probability on failure prediction of bridges, e.g., the prediction probability of fatigue failure carried out by Li and Mahmoodian [28], but they did not go one step further for risk-cost optimization and maintenance plan development.

This paper intends to fill the research gaps mentioned above and develop a bridge maintenance strategy based on risk-cost optimization. Five common failure modes are considered for the deteriorated bridge: flexure, shear, deflection, fatigue failure for the girder, and chloride attack for the concrete deck. The load effect of each failure mode is modeled as a stochastic process to consider the deterioration. The degradation effect 
of corrosion on the mechanical properties of bridge steel is considered in the modeling. The first passage probability theory and system reliability analysis theory are used for the time-dependent reliability of bridges considering multiple failure modes of different bridge components. A risk-cost optimization program is then applied to the bridge to develop an optimum maintenance plan based on the reliability analysis outcome. A working example is conducted to demonstrate the application of the proposed maintenance strategy on an existing bridge. The significance of the research is in advancing the knowledge in the failure prediction and maintenance of deteriorated structures.

\section{Formulation of Maintenance Strategy}

The bridge system consists of many components (e.g., deck, girder, etc.). A component can fail in many modes (namely, limit state). This paper focused on a steel-concrete composite bridge with the configuration shown in Figure 1, which is a common bridge type [30]. The failure of this bridge system is logically expressed in Figure 2. The system was modeled as a series system because maintenance needs to be performed when there is a violation of the limit state for any failure modes [28]. It is worth noting that bridge decks are usually overdesigned [31,32]. Thus, their flexure, shear deflection, and fatigue failure modes were not considered. Additionally, deterioration is normally inspected on bridge decks and girders for this bridge type [2]. Hence, the failure of bridge piers was not considered in this study.

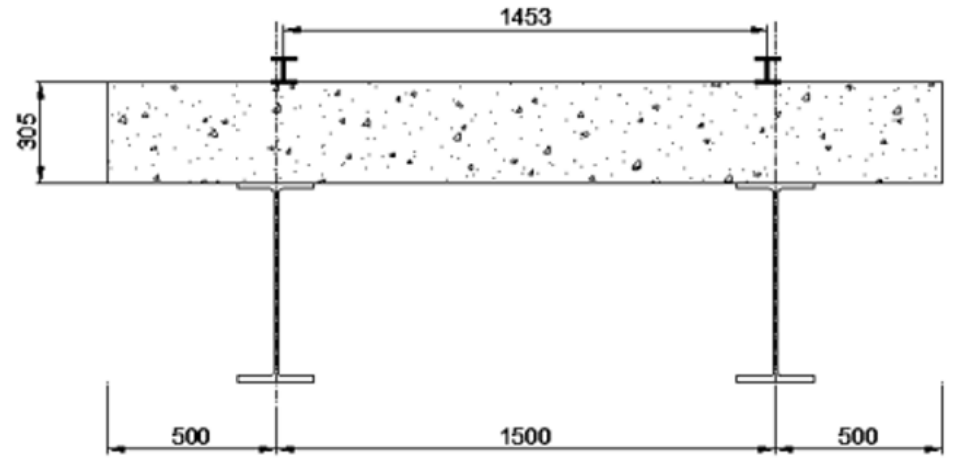

(a)



(b)

Figure 1. Configuration of the bridge in the working example (Unit: mm). (a) Girder system, (b) Cross-section of girder. 


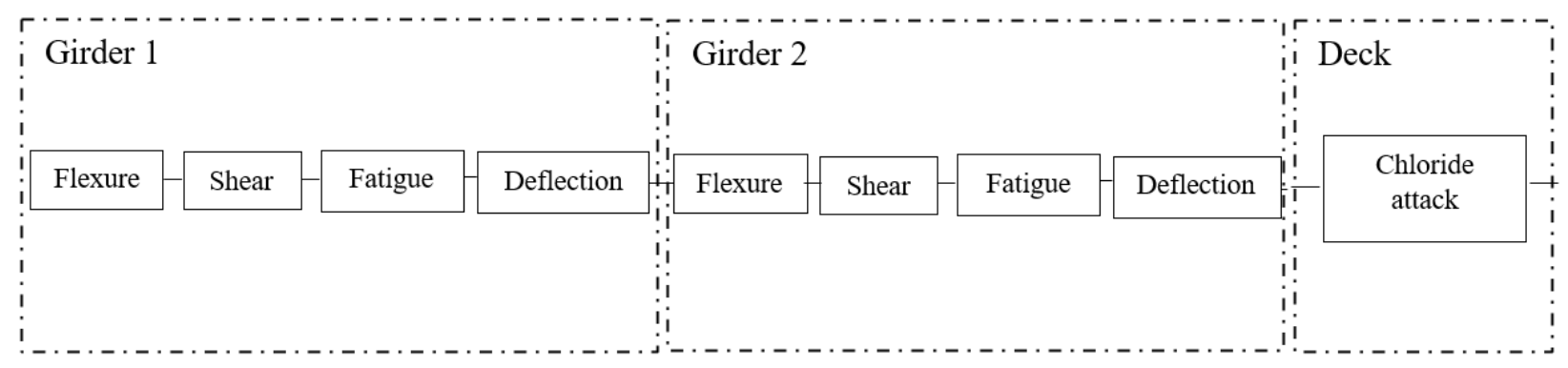

Figure 2. Schematic diagram of the bridge system.

The maintenance strategy for the bridge was developed by combining the concepts of system reliability and optimization. The justification for the maintenance strategy was that the maintenance will only be carried out when the probability of failure determined by any failure modes is greater than the acceptable limit, and the probability of whole bridge system failure is kept below the acceptable failure mode [16]. Considering this justification, the merit of developing this maintenance strategy was to minimize, if not eliminate, the number of maintenance actions without affecting the safety of the bridge. The problem can then be expressed mathematically as follows [17]:

$$
\begin{gathered}
\text { Minmize Risk }=\sum_{i=1}^{N_{r}} \sum_{j=1}^{N_{c}} \sum_{k=1}^{N_{m}} p_{f s, s}\left(t_{i}\right) \times C_{j k}\left(t_{i}\right) \\
\text { Subject to } p_{f}\left(t_{j}\right) \leq P_{f, a} \\
p_{f s, s}\left(t_{j}\right) \leq P_{f s, s a} \\
0 \leq t_{j} \leq t_{L}
\end{gathered}
$$

where $t_{i}$ is the maintenance time sequence with $i$ referring to the number of times, $j$ to structural component, and $i$ to failure mode. $N_{r}$ is the number of maintenance actions, $N_{\mathcal{C}}$ is the number of components, and $N_{m}$ is the number of failure modes for each component. $C_{j k}$ is the cost (including interest rate) of failure for the $j$ th component due to the $k$ th failure mode. $p_{f}$ and $P_{f, a}$ are the probability and acceptable probability of each failure mode. $p_{f s, s}$ and $P_{f s, s a}$ are the probability of failure and the acceptable probability of failure for the bridge system. Both $P_{f, a}$ and $P_{f s, s a}$ were determined as $0.011 \%$ based on AS 5100.1 [33]. $t_{L}$ is the lifetime of the structure.

The optimization (Equation (1)) finds the number of maintenances $N_{r}$ and the time of each maintenance, i.e., $t_{i}$. The most influential component within the system can also be determined at each maintenance time through this optimization. To be specific, the probabilities of failure of different components were determined and ranked (shown later in Equation (5)) in this optimization process. The component with the highest probability of failure was treated as the critical component, as bridge structure was considered a series system in this study. The maintenance action was only performed on the critical component and the cost of failure related to the repair for this component. This is shown schematically in Figure 3. Furthermore, the failure mode with the highest failure probability was repaired for the critical component. 


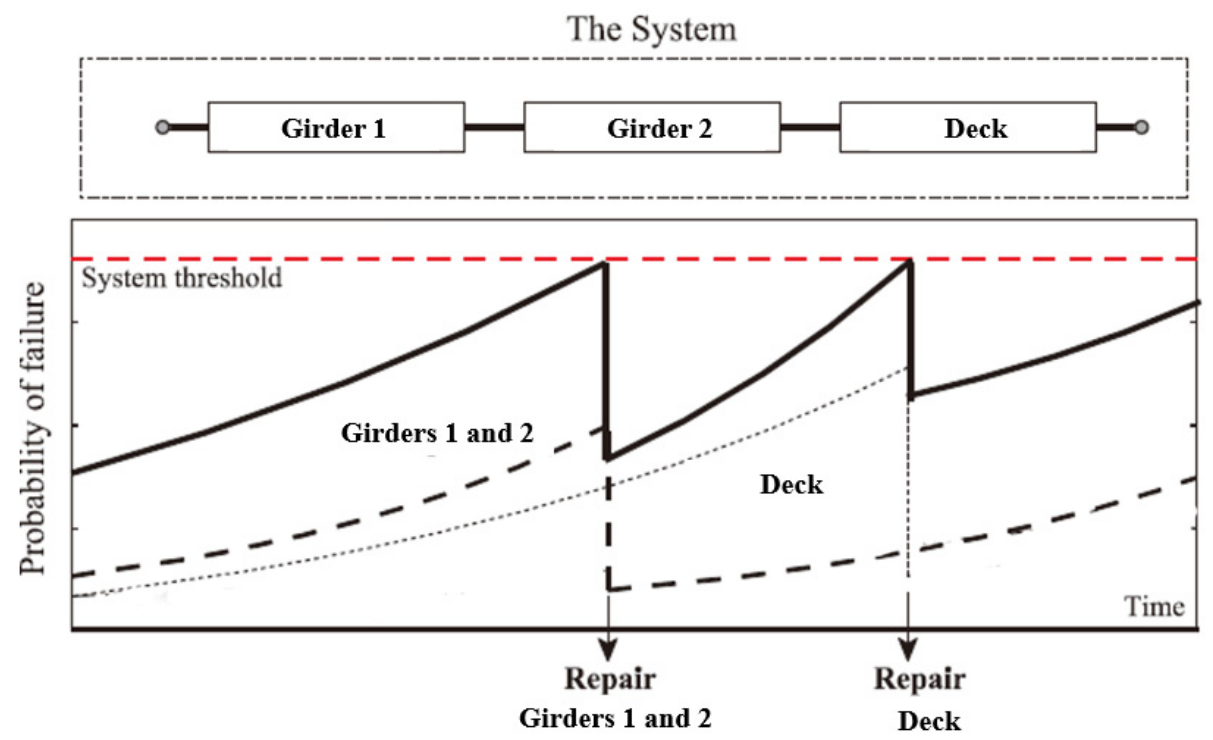

Figure 3. Maintenance strategy for the bridge system.

The probability of bridge failure $p_{f}$ for each failure mode in Equation (1) can be determined as follows:

$$
p_{f}(t)=P[G(S, R, t) \leq 0]=P[R(t) \leq S(t)]
$$

where $P$ denotes the probability of an event. $S(t)$ is the bridge response and $R(t)$ is the structural resistance. $G$ is the limit state function, which is $G(S, R, t)=R(t)-S(t)$.

Equation (2) represents a typical down-crossing problem, which can be determined using first passage probability theory [29]. In time-dependent reliability methods, the structural failure depends on the time that is expected to elapse before the first occurrence of the stochastic process, $R(t)$, down-crossing a critical limit, $S$, sometimes in a given time period $\left[0, t_{L}\right]$. Equally, the probability of failure, $p_{f}(t)$, can be determined based on the probability of the first occurrence of such an excursion during that period. This is known as "first-passage probability" and under the assumption of Poisson processes it can be expressed as follows [29]:

$$
p_{f}(t)=1-\left[1-p_{f}(0)\right] e^{-\int_{0}^{t} v d t}
$$

where $p_{f}(t)$ is the probability of structural failure at time $t=0$ and $v$ is the mean rate for $R(t)$ to down-cross critical limit (S). Based on Li and Melchers [29], the mean downcrossing rate is very small in practical problems. Thus, Equation (3) can be rewritten as follows:

$$
p_{f}(t)=p_{f}(0)+\int_{0}^{t} v d t .
$$

The down-crossing rate in Equation (4) can be determined by Li and Melchers [34] by assuming $R(t)$ follows Gaussian distribution.

As mentioned earlier in this section, the bridge structure was considered as a series system. It was also assumed that the structural components and failure modes were probabilistically independent, which gave a conservative estimation on system probability of failure based on Li and Mahmoodian [28]. According to the theory of reliability, the system probability of failure of component $p_{f s, c}(t)$ and bridge $p_{f s, s}(t)$ at time $t$ can be estimated as follows [35]:

$$
p_{f s, c}(t) \text { or } p_{f s, s}(t)=1-\prod_{i=1}^{m}\left[1-p_{f, i}(t)\right]
$$


where $m$ represents the number of failure modes in the series system.

\section{Stochastic Model}

It is known that the bridge resistance $R(t)$ is a very random phenomenon, dependent on many factors including the corrosion rate, the geometry of cross-section, load frequency and load effect [36]. It is justifiable to model $R(t)$ as a stochastic process because of deterioration, which is expressed in primary contribution factors and treated as basic random variables. It follows that the load effect $R(t)$ can be modeled as a function of the basic random variables and time, expressed as follows:

$$
R(t)=f\left(X_{1}, X_{2}, \cdots, X_{n}, t\right)
$$

where $X_{1}, X_{2}, \cdots, X_{n}$ are the basic random variables, the probabilistic information of which are (presumed) available. With this treatment, the mean $\mu_{R}()$ and standard deviation $\sigma_{R}()$ of $R(t)$ can be obtained using Monte Carlo simulation [29].

To consider the randomness $R(t)$ a random variable, $\xi_{R}$, is introduced, which can be defined in such a way that its mean is unity (i.e., $E\left(\xi_{R}\right)=1$ ) and its coefficient of variation is $\lambda_{R}=\frac{\sigma_{R}}{\mu_{R}}$ [29]. Thus, $R(t)$ can be expressed as follows:

$$
R(t)=R_{c}(t) \xi_{R}
$$

where $R_{c}(t)$ is treated as a pure time function of structural resistance. The next section shows the calculation of $R_{\mathcal{c}}(t)$ for different failure modes. The mean and auto-covariance function of $R_{c}(t)$ can be determined as follows [29]:

$$
\begin{aligned}
& \mu_{R}(t)=E\left[R_{c}(t)\right]=R_{c}(t) \cdot\left[\xi_{R}\right]=R_{c}(t), \\
& C_{R R}\left(t_{i}, t_{j}\right)=\rho \lambda_{R}\left(t_{i}\right) \lambda_{R}\left(t_{j}\right) R_{c}\left(t_{i}\right) R_{c}\left(t_{j}\right)
\end{aligned}
$$

where $\rho$ is the autocorrelation coefficient for $R(t)$ between two points in time $t_{i}$ and $t_{j}$, which can be obtained by experiments and field studies.

\section{Failure Mode}

As mentioned previously, a performance criterion should be established to assess the risk of failure. In the structural reliability theory, this criterion can be expressed in the form of limit state function. The limit state functions for a bridge girder and deck under different performance criteria (failure modes) are presented in this section.

Flexural failure (Girder). The limit state function can be written as follows for flexure failure.

$$
G\left(M_{R}, M_{S}, t\right)=M_{R}(t)-M_{S}
$$

where $M_{R}(t)$ is the flexural resistance of steel section at time $t$ and $M_{S}$ is the flexural moment due to the load effect, which is treated as a deterministic parameter in this research. Moreover, $M_{R}(t)$ and $M_{S}$ are resistance and load effect at the mid-span. $M_{R}(t)$ is computed based on Australian Standard (AS 5100.6 2017):

$$
M_{R}(t)=\sigma_{y e}(t) Z_{e}(t)
$$

where $Z_{e}(t)$ is the effective section modulus of mid-girder of the span, and $\sigma_{y e}(t)$ is the yield strength of the girder at mid-span at time $t$. The bending moment $M_{S}$ is case-specific. The value is presented in Section 7 for the working example.

Shear Failure (Girder). The limit state function can be written as follows for shear failure.

$$
G\left(V_{R}, V_{S}, t\right)=V_{R}(t)-V_{S}
$$


where $V_{R}(t)$ is the shear resistance of girder at time $t . V_{S}$ is the shear force due to load effects. $V_{R}(t)$ is calculated as follows (AS 5100.6 2017):

$$
V_{R}(t)=0.6 \sigma_{y e}(t) A_{w}(t)
$$

where $A_{w}(t)$ is the steel web section area at time $t$. The shear force $V_{S}$ is also case-specific with values shown in Section 7.

Deflection Failure (Girder). For deflection failure, the limit state function is calculated as follows:

$$
G\left(\Delta_{R}, \Delta_{S}, t\right)=\Delta_{R}-\Delta_{S}(t)
$$

where $\Delta_{R}$ is the allowable deflection under live load. According to Australian Standard (AS5100.2 2017), maximum mid-span deflection under live load should not exceed 1/640 of the span length. $\Delta_{S}$ is the deflection at the middle of the span due to live load effect at time $t$. $\Delta_{S}$ is case-specific, which can be calculated based on the elastic modulus of steel, the second moment of inertia of girder cross-section, corrosion rate, and time.

Fatigue Failure (Girder). For fatigue failure, the limit state function is calculated as follows:

$$
G(D, \Delta, t)=D(t)-\Delta
$$

where $\Delta$ is the threshold that is equal to $1, D(t)$ is the Miner's damage accumulation index at time $t$, which can be determined as follows [37]:

$$
D(t)=\frac{\operatorname{num}(t)}{A(t)} E\left[S_{s}(t)^{B(t)}\right]-\Delta
$$

where $A(t)$ and $B(t)$ are the fatigue strength coefficient and fatigue strength exponent. $S_{S}$ is the stress range. The detailed explanations of $A, B$ and $S_{S}$ are given in Li et al. (2020). $n u m(t)$ is the total number of fatigue stress cycles applied during time $t$, which can be determined as follows [37]:

$$
\operatorname{num}(t)=f_{\text {load }} t
$$

where $f_{\text {load }}$ is the load frequency in the lifetime and $t$ is time in years.

$E\left[S_{S}(t)^{B(t)}\right]$ is the expected value of $S_{S}{ }^{B}$ at time $t$, which can be calculated as follows [37]:

$$
E\left[S_{s}(t)^{B(t)}\right]=\left(\sqrt{2} S_{s o}(t)\right)^{B(t)} \Gamma\left(\frac{B(t)}{2}+1\right)
$$

where $S_{s o}(t)$ is a statistical parameter at time $t$, which can be determined as follows:

$$
S_{s o}(t)=\sqrt{\frac{\pi}{2}} E\left[S_{S}(t)\right]
$$

where $E\left[S_{S}(t)\right]$ is the mean stress effect at time $t$, which can be either a normal stress effect or a shear stress effect. The mean stress effect can be determined based on the maximum stress and minimum stress in the largest load cycle as follows [36]:

$$
E\left[S_{s}(t)\right]=\frac{\sigma_{\max }(t)+\sigma_{\min }(t)}{2}
$$

where $\sigma_{\max }(t)$ and $\sigma_{\min }(t)$ are the maximum and minimum stress on the girders. They can be determined by using the maximum and minimum bending moments the girder is subjected to (i.e., $M_{\max }$ and $M_{\text {min }}$ ) divided by the selection modulus $Z_{e}(t)$. The values of $M_{\max }$ and $M_{\min }$ are case-specific with values shown in Section 7.

Chloride concentration (bridge deck). It is essential to make sure that the chloride concentration within the concrete bridge is below the threshold value, so that the deteriora- 
tion of reinforcement can be avoided. The relevant limit state can thus be established as follows [38]:

$$
G\left(C, C_{0}, t\right)=C(t)-C_{O}
$$

where $C(t)$ is the chloride concentration at the position of the steel reinforcement (\%, the percentage of chloride in the mass of concrete is used as the unit of chloride concentration in this paper). $C_{0}$ is the critical threshold chloride concentration that initiates the corrosion of reinforcement, which is $0.05 \%$ [38]. The chloride concentration $C(t)$ at time $t$ is as follows [38]:

$$
C(t)=C_{s}\left[1-\operatorname{erf}\left(\frac{c}{2 \sqrt{t D_{f}}}\right)\right]
$$

where $C_{0}$ denotes the initial concrete concentration in concrete. $D_{f}$ is the diffusion coefficient $\left(\mathrm{mm}^{2} /\right.$ year) and erf is the error function. $c$ is the cover thickness for slab reinforcement.

All the limit state functions presented in this section can be rewritten into the formats in which $R(t)$ is a stochastic process and down-crosses the deterministic threshold $S$ (e.g., $R(t)$ and $S$ can be $-\Delta_{S}(t)$ and $-\Delta_{R}$ in Equation (14)). Thus, time-dependent probability of failure for each performance criterion of the bridge can be calculated by Equations (3) and (4) and Li and Melchers [34].

\section{Corrosion Models}

The deterioration of steel girders is caused by corrosion. It is widely accepted to use average corrosion loss (thickness loss) to represent the corrosion degree of bridge girders [39]. It is assumed that corrosion happens uniformly across girders. The average corrosion loss can be calculated as follows [39]:

$$
C_{r}(t)=K t^{n}
$$

where $C_{r}(t)$ is the average corrosion penetration in micrometers $\left(10^{-3} \mathrm{~mm}\right)$ at time $t$. The model parameters $K$ and $n$ were determined as $0.0802 \mathrm{~mm}$ and 0.593 for the structural components in an urban environment [39]. Based on Equation (23), the changes in geometry of steel girders over time can be determined.

It can be seen from Equations (11), (13) and (16) that the changes in yield strength $\sigma_{y e}(t)$, fatigue strength coefficient $A(t)$, and fatigue strength exponent $B(t)$ over time from corrosion can be determined as follows for low-carbon bridge steel (e.g., G250 steel) [2,28].

$$
\begin{gathered}
\sigma_{y e}(t)=\sigma_{\text {yeo }}\left(1+0.003428 C_{r}(t)-0.034498 C_{r}(t)+0.006139\right), \\
A(t)=-9 \times 10^{20} \operatorname{cr}(t)+1 \times 10^{20}, \\
B(t)=-12.59 c r(t)+5.4589
\end{gathered}
$$

where $\sigma_{\text {yeo }}$ is the yield strength of steel before corrosion, and $c r(t)$ is the corrosion rate, which can be determined as follows:

$$
c r(t)=\frac{d C_{r}(t)}{d t}=K n t^{n-1}
$$

\section{Risk-Cost Optimization}

Each item in Equation (1) can be developed based on Equations (2)-(27). A computational procedure of optimization was developed, as shown in Figure 4. The stochastic models of $R(t)$, including $M_{R}(t), V_{R}(t), \Delta_{S}(t), D(t)$, and $C(t)$, were used as inputs. The optimization steps shown in Figure 4 are summarized as follows: 


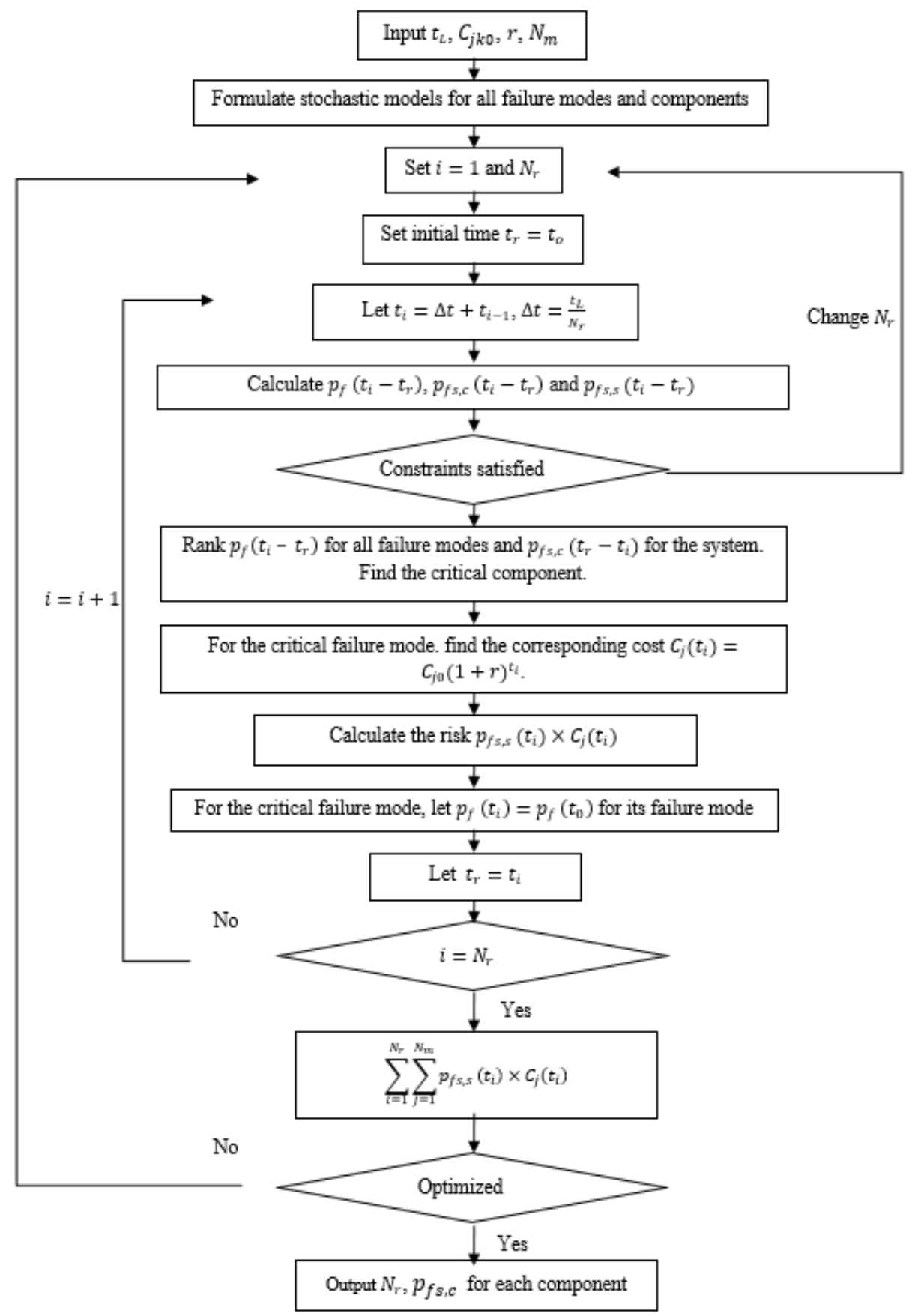

Figure 4. Program for maintenance strategy optimization.

1. Set lifetime $t_{L}$, the failure cost of each failure mode at initial time $C_{j k 0}$, the interest rate $r$, and the total number of failures mode $N_{m}$.

2. Formulate stochastic models of $R(t)$ for different failure modes, as listed in Section 4 .

3. Set the total number of maintenance times $N_{r}$ and let $i=1$.

4. Set an initial time, $t_{0}=0$. Then, set the maintenance time for bridge $t_{r}=t_{0}$

5. Let $\Delta t=\frac{t_{L}}{N_{r}}$ and $t_{i}=\Delta t+t_{i-1}$.

6. For a given time $t_{r}$, calculate the probability of failure for each failure mode $p_{f}\left(t_{r}-t_{i}\right)$ based on Li and Melchers [29], the probability of failure for each component $p_{f_{s, c}}\left(t_{r}-t_{i}\right)$ and bridge system $p_{f_{s, s}}\left(t_{r}-t_{i}\right)$ using Equations (2)-(5).

7. Check the constraints shown in Equation (1). If the constrain is not satisfied, repeat step (3) with a different $N_{r}$ until the constrain is satisfied. Otherwise, go to step 8 . 
8. Rank $p_{f}\left(t_{i}-t_{r}\right)$ for all failure modes and $p_{f s, c}\left(t_{r}-t_{i}\right)$ for the system. Based on the ranking, the critical component and its failure mode can be determined. This step determines the repair location (based on the component).

9. For the critical component identified in step 8 , determine the cost of failure $C_{j k}=$ $C_{J K 0}(1+r)^{t_{i}}$.

10. Calculate the risk, $p_{f s, s} \times C_{j k}$, where $p_{f s, s}$ is determined in step (4) and $C_{j k}$ is determined in step (7).

11. Reset the process, namely, for the critical component, let $p_{f}\left(t_{i}\right)=p_{f}\left(t_{0}\right)$ for all its failure modes. It is assumed that when a critical component has been repaired (e.g., strengthening has been carried out on bridges), the probability of failure for its failure mode is reduced to the value at the initial time.

12. Let $t_{r}=t_{i}$

13. Let $i=i+1$. Repeat steps (4)-(12), until all the maintenances are completed, i.e., $i=N_{r}$.

14. Repeat steps (2)-(13) for a range of $N_{r}$ values and find the optimum value corresponding to the minimum risk: output $N_{r}$ and $p_{f s, c}$ for each component.

The search for $N_{r}$ with given constraints is an iterative procedure. Based on Baji et al. [16], the Genetic Algorithm method [16] is an efficient method in finding the optimum of complex problems with nonlinear constrains. Thus, in this paper. the flowchart in Figure 4 was coded using the Genetic Algorithm through MATLAB. As inputs, $t_{L}, C_{j k 0}$ and $r$ are case-specific with values summarized in Section 7 for the case study bridge. $N_{m}=9$ in this study. Since the maintenance of bridge is generally carried out every 5 years, the initial value of $N_{r}$ can be determined by letting $N_{r}=\frac{t_{L}}{\Delta t}$, where $\Delta t=5$ [40].

\section{Working Example}

Configuration of the structural system. The proposed methodology was applied to a railway bridge as a working example. Maintenance had just been carried out for the bridge and it was assumed that the bridge would last for a further 60 years. Thus, $t_{L}=60$ (years). The railway bridge had one span, and the length of the span was $12 \mathrm{~mm}$. The bridge contained two supported girders, as shown in Figure 1a. The geometry of girder is shown in Figure 1b. The flange width and thickness were 229 and $19.6 \mathrm{~mm}$, respectively. The web depth and thickness were 572 and $11.9 \mathrm{~mm}$, respectively. These parameters were treated as normally distributed variables to consider the changes in the cross-section along the girders. The coefficient of variance (COV) for these parameters was 0.02 based on $\mathrm{Li}$ [2]. The girders were made of G250 low carbon steel with average yield strength $\left(\sigma_{\text {yeo }}\right)$ of 320 MPa before corrosion and an elastic modulus of $210 \mathrm{GPa}$. They were normally distributed random variables, with both COVs equal to 0.02 to consider the uncertainties due to steel manufacturing tolerances [2].

The deck slab was $2.5 \mathrm{~m}$ wide and $305 \mathrm{~mm}$ thick with a specific concrete strength of 34.5 MPa. Reinforcing steel was Grade 40. Diffusion coefficient $D_{f}$ for chloride was determined as $31.5 \mathrm{~mm}^{2} /$ year [38]. The coefficient followed lognormal distribution with COV of 0.20 . The cover thickness of slab reinforcement $c$ was $30 \mathrm{~mm}$, which followed normal distribution and had a COV of 0.02 [38]. Surface chloride content $C_{0}$ was $0.8 \%$ with COV of 0.5 , following lognormal distribution [38].

Bridge load modeling. The loading needed to be determined for the bridge girders. Based on the Department of Railway Transportation data, the superimposed dead load on the girder (including the self-weight of the deck, the railway ballast and track, and the weight of overhead structures) was determined to be $19.2 \mathrm{kN} / \mathrm{m}$. Trains operating on the viaduct had four motor cars and two trailer cars. The axle load was $118 \mathrm{kN}$ for a motor car $\left(P_{1}\right)$ and $108.5 \mathrm{kN}$ for a trailer car $\left(P_{2}\right)$ for the tracks, as shown in Figure 5 . The frequency of the train was 80 per day with COV of 0.05 [2]. 


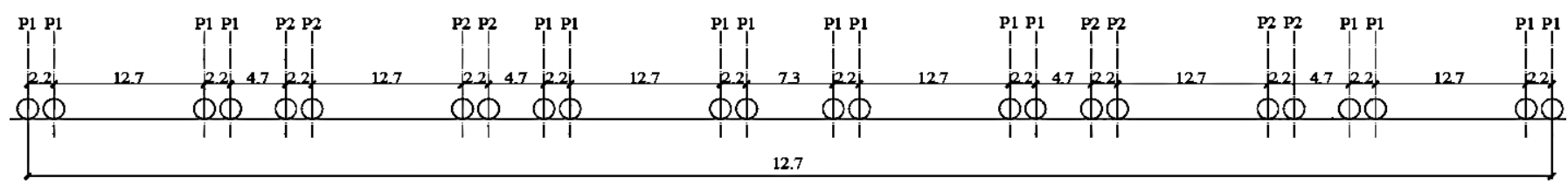

Figure 5. Axle load system on each of the four tracks [2].

Based on the above information, $M_{S}$ and $V_{S}$ were determined as follows:

$$
\begin{gathered}
M_{s}=\frac{q l^{2}}{8}+\frac{1}{4} P_{1} l+\frac{P_{1}}{2}\left(\frac{l}{2}-x_{1}\right)+\frac{P_{2}}{2}\left(\frac{l}{2}-x_{2}\right)+\frac{P_{2}}{2}\left(\frac{l}{2}-x_{3}\right), \\
V_{s}=\frac{q l}{8}+P_{1}+P_{1}\left(\frac{l-x_{1}}{l}\right)+P_{2}\left(\frac{l-x_{2}}{l}\right)+P_{2}\left(\frac{l-x_{3}}{l}\right)
\end{gathered}
$$

where $l$ is the length of the girder, $q$ is the uniform disturbed load calculated based on the self-weight of the girder and superimposed dead load $(19.2 \mathrm{kN} / \mathrm{m}) . x_{1}, x_{2}$ and $x_{3}$ were determined based on Figure 5, and were 2.2, 6.9, and $9.1 \mathrm{~m}$, respectively. Also, $M_{\max }=M_{\mathcal{S}}$ and $M_{\text {min }}=\frac{q l^{2}}{8}$ to determine the mean stress effect in Equation (20) for fatigue damage calculation.

For deflection failure, $\Delta_{S}$ was calculated as follows:

$$
\Delta_{S}(t)=\frac{P_{1} l^{3}}{48 E I(t)}+\frac{P_{1}\left(\frac{l}{2}-x_{1}\right) \times\left[3 l^{2}-\left(\frac{l}{2}-x_{1}\right)^{2}\right]}{48 E I(t)}+\frac{P_{2}\left(\frac{l}{2}-x_{2}\right) \times\left[3 l^{2}-\left(\frac{l}{2}-x_{2}\right)^{2}\right]}{48 E I(t)}+\frac{P_{1}\left(\frac{l}{2}-x_{1}\right) \times\left[3 l^{2}-\left(\frac{l}{2}-x_{1}\right)^{2}\right]}{48 E I(t)}
$$

where $E$ is the elastic modulus of steel and $I(t)$ the second moment of inertia of the girder

\begin{tabular}{|c|c|c|c|c|c|}
\hline Symbol & Parameter & Statics Distribution & Mean & $\mathrm{COV}$ & Resource \\
\hline$C_{0}$ & Surface chloride content & \multirow{4}{*}{ Lognormal distribution } & $0.8 \%$ & 0.3 & \multirow{2}{*}[38]{} \\
\hline$D_{f}$ & Diffusion coefficient & & 31.5 & 0.2 & \\
\hline$K$ & Model parameter of corrosion & & $0.0802 \mathrm{~mm}$ & 0.15 & \multirow{2}{*}[41]{} \\
\hline$n$ & Model parameter of corrosion & & 0.593 & 0.01 & \\
\hline$b_{f}$ & Flange width at $t=0$ & \multirow{8}{*}{ Normal distribution } & $229 \mathrm{~mm}$ & 0.02 & \multirow{12}{*}{$\begin{array}{l}\text { Data from the } \\
\text { Department of Railway } \\
\text { Transportation }\end{array}$} \\
\hline$d_{f}$ & Flange thickness at $t=0$ & & $19.6 \mathrm{~mm}$ & 0.02 & \\
\hline$b_{w}$ & Web length at $t=0$ & & $572 \mathrm{~mm}$ & 0.02 & \\
\hline$d_{w}$ & Web thickness at $t=0$ & & $11.9 \mathrm{~mm}$ & 0.02 & \\
\hline$c$ & $\begin{array}{l}\text { Cover thickness of slab } \\
\text { reinforcement }\end{array}$ & & $30 \mathrm{~mm}$ & 0.02 & \\
\hline$f$ & Train frequency & & 80 per day & 0.05 & \\
\hline$E$ & Elastic modulus of girder steel & & $210 \mathrm{GPa}$ & 0.02 & \\
\hline$\sigma_{\text {yeo }}$ & Yield strength of steel at $t=0$ & & $320 \mathrm{MPa}$ & 0.02 & \\
\hline$q$ & Imposed load on girder & \multirow{5}{*}{ Constant } & $0.92 \mathrm{kN} / \mathrm{m}^{2}$ & - & \\
\hline$P_{1}$ & Axle load for a motor car & & $118 \mathrm{kN}$ & - & \\
\hline$P_{2}$ & Axle load for a trailer car & & $108.5 \mathrm{kN}$ & - & \\
\hline$l$ & Total length of the girder & & $12 \mathrm{~m}$ & - & \\
\hline$C_{O}$ & $\begin{array}{l}\text { Critical threshold chloride } \\
\text { concentration }\end{array}$ & & $0.05 \%$ & - & {$[38]$} \\
\hline
\end{tabular}
cross-section at time $t$. All the basic variables are summarized in Table 1.

Table 1. Values of basic variables.

Probability of failure prediction. Based on the basic variables summarized in Table 1, the probability of failure of each failure mode was determined. In detail, for flexure failure, $M(t)$ was determined by Equations (11), (23) and (24) based on the geometry and yield strength of the girder summarized in Table 1. $M_{S}$ was determined by Equation (28). For shear failure, $V(t)$ was determined by Equations (13), (23) and (24) based on the geometry 
of web and yield strength of the girder summarized in Table 1. $V_{s}$ was determined by Equation (29). For deflection failure, $\Delta_{S}(t)$ was determined by Equations (23) and (30), and $\Delta_{R}$ was determined as $0.019 \mathrm{~m}(l / 640)$.

For fatigue failure $D(t), n(t)$ were determined by Equation (17) based on the load frequency. $A(t)$ and $B(t)$ were determined by Equations (25)-(27). $E[S(t)]$ was determined by Equations (18)-(20), and (26) based on parameters in the corrosion model, sectional geometries, the maximum and minimum bending moment for girder. For chloride attack $C(t)$ was determined based on Equation (22). The statistics of $M(t), V(t), \Delta_{S}(t), D(t), C(t)$ were obtained using Monte Carlo simulation. A sample size of 1,000,000 was found to achieve a reasonable accuracy (convergence) in simulating each parameter [2].

With variables given in Table 1 and the above preparations, the probability of failure of different failure modes was determined by Li and Melchers [29] over time. The probability of failure of each failure mode was the same for the two girders as they were subjected to identical loading conditions. The corrosion effect on sectional properties and mechanical properties at any point of time was related to the corrosion effect in previous times [37]. Therefore, there was a high autocorrelation among the corrosion effects at each point in time, and autocorrelation coefficient $\rho$ was selected as 0.9. It can be seen from Figure 6 that probability of failure for fatigue was the highest at each time point. This indicated that fatigue failure is the most critical failure mode for the bridges, and more care should be taken to protect the girder from fatigue damage. The changes in probability of failure for different bridge components (i.e., girders and deck) and the entire bridge system were then determined based on Equations (2)-(5), with the results shown in Figure 7.

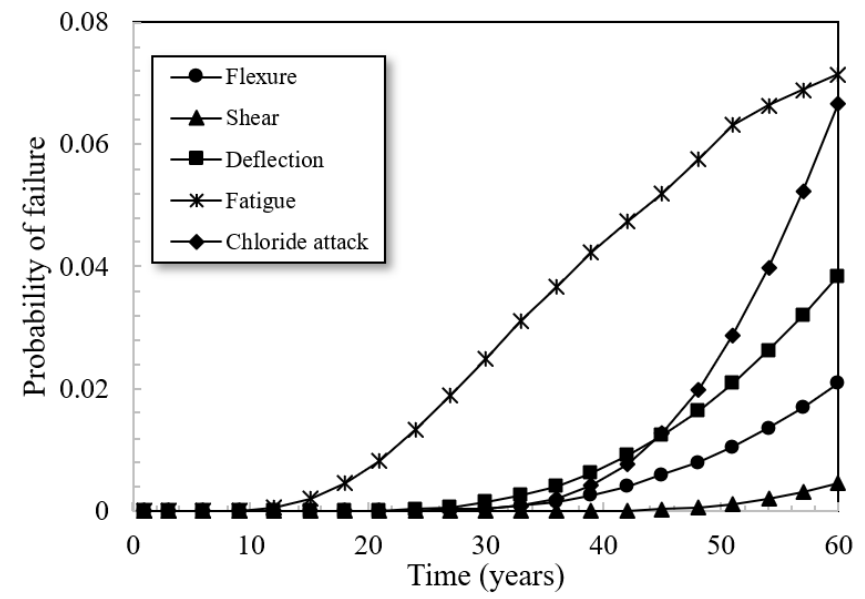

Figure 6. Probability of failure for different failure modes.

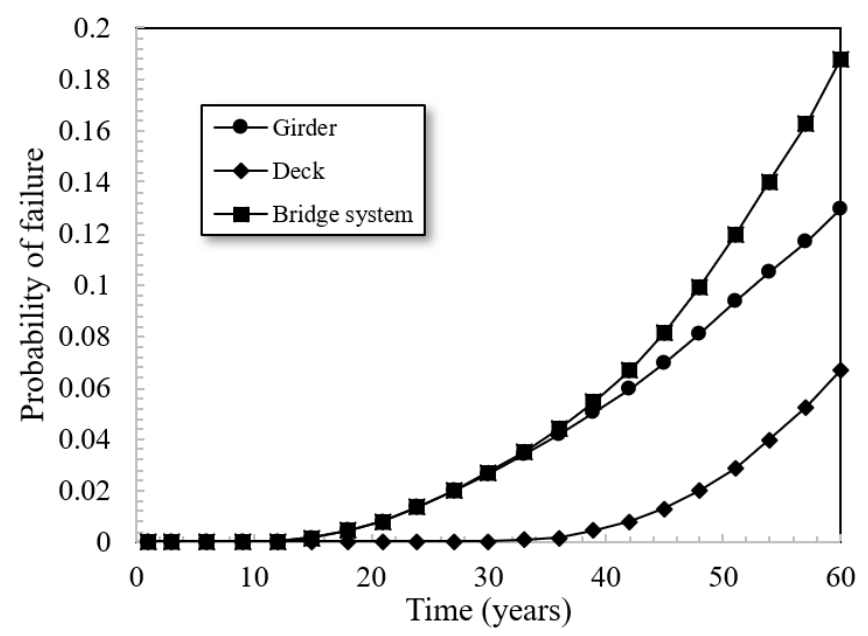

Figure 7. System probability of failure of the bridge and its components. 
Development of maintenance strategies. A risk-cost program was used to minimize the risk based on Figure 4 and a developed MATLAB code. The program determined the number and period of maintenance that minimized the total risk of steel structures. As inputs for the program, the lifetime of steel structures $t_{L}$ was 60 years. The cost of failure $C_{j k 0}$ at initial time was USD 5,000,000 for each failure mode of the girder and USD 79,000 for the deck $[42,43]$. The interest rate $r$ was $2 \%[16,44]$. The optimization program ran for a range of $N_{r}$ values and the results are shown in Figure 8. Based on Figure 8, nine maintenance actions could be performed to minimize the risk, e.g., $N_{r}=9$, and the period of maintenance $\Delta t$ was 6 years. The location of each maintenance is summarized in Table 2. Primarily, the maintenance of girders against fatigue failure could be carried out by fixing fatigue cracks, removing rust, and using fiber-reinforced plastic to strengthen the bridge girder at mid-span, with details summarized in Aidoo et al. [45]. Moreover, spraying alkali-metal salts (e.g., $\mathrm{NaHCO}_{3}$ ) on the concrete surface could reduce the chloride concentration [46] and maintain the deck against chloride attack.

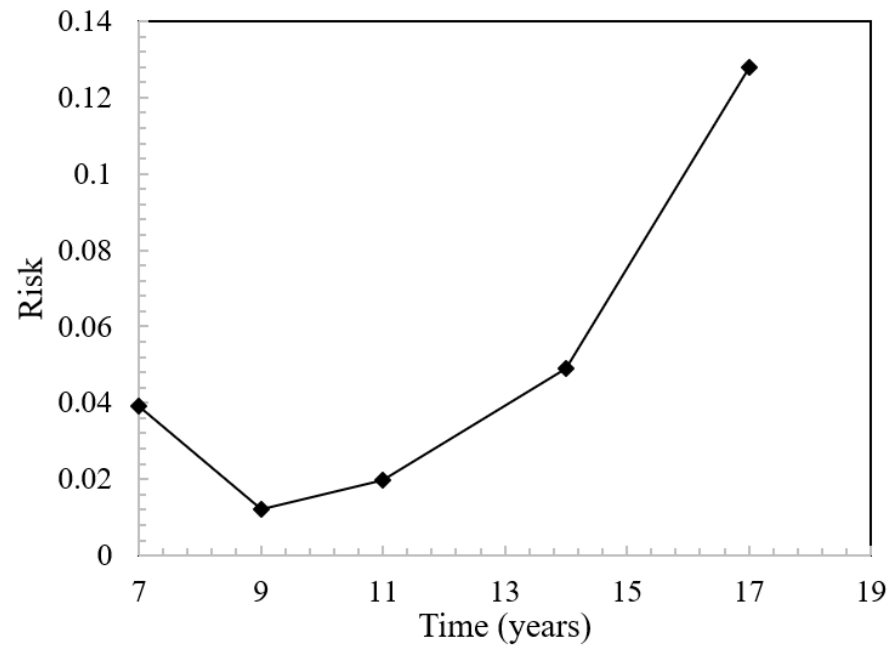

Figure 8. Derivation of the optimum number of maintenance actions.

Table 2. Optimized maintenance strategy.

\begin{tabular}{cccc}
\hline Number & Time (Years) & Component & Failure Mode \\
\hline 1 & 6 & Girders 1 and 2 & Fatigue \\
\hline 2 & 12 & Girders 1 and 2 & Fatigue \\
\hline 3 & 18 & Deck & Chloride attack \\
\hline 4 & 24 & Girders 1 and 2 & Fatigue \\
\hline 5 & 30 & Girders 1 and 2 & Fatigue \\
\hline 6 & 36 & Deck & Chloride attack \\
\hline 7 & 42 & Girders 1 and 2 & Fatigue \\
\hline 8 & 48 & Girders 1 and 2 & Fatigue \\
\hline 9 & 54 & Deck & Chloride attack \\
\hline
\end{tabular}

\section{Limitations}

Although the study proposed a maintenance strategy for bridges, there are still several limitations. Firstly, the autocorrelation coefficient $\rho$ was assumed to be 0.9 in the failure probability calculation for each failure mode. Technically, $\rho$ needs to be determined by measuring the corrosion effects (corrosion loss, degradation in yield strength and fatigue strength) of the bridge at different times and calculated based on Li and Melchers [34]. Thus, future works will be carried out to measure the corrosion effects for bridges and 
acquire a more reliable $\rho$ value. Secondly, the loading $S$ was treated as a deterministic value in calculating the probability of failure for each failure mode. In future work, it will be worthwhile to treat structural resistance $S(t)$ as a stochastic process and consider various factors influencing $S(t)$. Thirdly, the probability of failure was determined by assuming that the structural components and failure modes were probabilistically independent. However, there is a correlation among different structural components and failure modes (e.g., the correlation between flexure and shear failure mode is high as they are determined using the same girder's loading condition). This correlation needs to be considered in future studies. Fourthly, it was assumed that the probability of failure for the critical component was reduced to the value at the initial time of repair in the risk-cost optimization algorithm. This is not realistic, and more work needs to be carried out to determine the changes in the probability of failure after repairing.

\section{Conclusions}

This paper developed a maintenance strategy for deteriorated bridges based on riskcost optimization. Five failure modes were considered for the deteriorated bridge, including flexure, shear, deflection and fatigue failure of the girder, and chloride attack on the concrete deck. The first passage probability theory and system reliability analysis theory were then used for the time-dependent reliability of bridges considering the failure modes of girders and decks. The degradation effect of corrosion on the mechanical properties of the bridge was considered in the reliability analysis. A risk-cost optimization program was then applied to find the maintenance strategies leading to the minimum risk. This method was applied to a working example. It was found, through reliability analysis, that the bridge was more vulnerable to fatigue failure on the girders, compared with other failure modes. It was also found that the developed maintenance strategy can predict when, where, and what to maintain for bridges. This will ensure safe and serviceable operation during their lifespan.

Author Contributions: Conceptualization, L.L.; methodology, L.L. and M.M.; software, L.L.; validation, L.L.; formal analysis, L.L.; investigation, L.L.; resources, L.L.; data curation, L.L.; writingoriginal draft preparation, L.L. and Z.S.; writing-review and editing, L.L. and M.M.; superision, M.M. and A.K.; All authors have read and agreed to the published version of the manuscript.

Funding: This research received no external funding.

Institutional Review Board Statement: Not applicable.

Informed Consent Statement: Not applicable.

Data Availability Statement: Not applicable.

Conflicts of Interest: The authors declare no conflict of interest.

\section{References}

1. Czarnecki, A.A.; Nowak, A.S. Time-variant reliability profiles for steel girder bridges. Struct. Saf. 2008, 30, 49-64. [CrossRef]

2. Li, L. Service Life Prediction of Bridges Subjected to Corrosion Using Time-Dependent Reliability Method. Ph.D. Thesis, RMIT University, Melbourne, Australia, 2018.

3. Kayser, J.R.; Nowak, A.S. Capacity loss due to corrosion in steel-girder bridges. J. Struct. Eng. 1989, 115, 1525-1537. [CrossRef]

4. Biezma, M.V.; Schanack, F. Collapse of steel bridges. J. Perform. Constr. Facil. 2007, 21, 398-405. [CrossRef]

5. Witcher, T.R. From disaster to prevention: The silver bridge. Civ. Eng. Mag. Arch. 2017, 87, 44-47. [CrossRef]

6. Wolmuth, B.; Surtees, J. Crowd-related failure of bridges. In Proceedings of the Institution of Civil Engineers-Civil Engineering; Thomas Telford Ltd.: Telford, UK, 2003; Volume 156, pp. 116-123.

7. Mahmoodian, M.; Alani, A.; Tee, K.F. Stochastic failure analysis of the gusset plates in the Mississippi river bridge. Int. J. Forensic Eng. 2012, 1, 153-166. [CrossRef]

8. Yanev, B.; Chen, X. Life-cycle performance of New York City bridges. Transp. Res. Rec. 1993, $1389,17$.

9. Mohammadi, J.; Guralnick, S.A.; Yan, L. Incorporating life-cycle costs in highway-bridge planning and design. J. Transp. Eng. 1995, 121, 417-424. [CrossRef]

10. AI-Subhi, K.M.; Johnston, D.W.; Farid, F. OPBRIDGE: An integrated bridge budget forcasting and allocation module at the state level. Transp. Res. Rec. 1990, 1268, 95-109. 
11. Tam, C.K.; Stiemer, S.F. Development of bridge corrosion cost model for coating maintenance. J. Perform. Constr. Facil. 1996, 10, 47-56. [CrossRef]

12. Frangopol, D.M. Chapter 9: Life-cycle cost analysis for bridges. In Bridge Safety and Reliability; Frangopol, D.M., Ed.; ASCE: Reston, VA, USA, 1999; pp. 210-236.

13. Estes, A.C.; Frangopol, D.M. Bridge lifetime system reliability under multiple limit states. J. Bridge Eng. 2001, 6, 523-528. [CrossRef]

14. Yang, I.T.; Hsu, Y.S. Risk-based Multiobjective Optimization Model for Bridge Maintenance Planning, In AIP Conference Proceedings; American Institute of Physics: College Park, MD, USA, 2010; Volume 1233, pp. 477-482.

15. Zhu, B.; Frangopol, D.M. Risk-based approach for optimum maintenance of bridges under traffic and earthquake loads. J. Struct. Eng. 2013, 139, 422-434. [CrossRef]

16. Baji, H.; Li, C.Q.; Scicluna, S.; Dauth, J. Risk-cost optimised maintenance strategy for tunnel structures. Tunn. Undergr. Space Technol. 2017, 69, 72-84. [CrossRef]

17. Melchers, R.E. Structural Reliability Analysis and Prediction; Wiley: Chichester, UK, 1999.

18. Stewart, M.G.; Rosowsky, D.V. Time-dependent reliability of deteriorating reinforced concrete bridge decks. Struct. Saf. 1998, 20, 91-109. [CrossRef]

19. Itoh, Y.; Liu, C. Multiobjective Optimization of Bridge Deck Maintenance. 1999, pp. 136-151. Available online: https://books.google.com.hk/books?hl=zh-CN\&lr=\&id=MJh0CHZ1F6MC\&oi=fnd\&pg=PA136\&dq=Multi+Objective+ optimization+of+bridge+deck+maintenance.\&ots=tNA3PUDKpC\&sig=yTbI3oN7JdFSla6wlWyNlrrLJt8\&redir_esc=y\&hl=zh$\mathrm{CN} \&$ sourceid $=\mathrm{cndr} \# \mathrm{v}=$ onepage $\& \mathrm{q} \& \mathrm{f}=$ false (accessed on 27 December 2021).

20. Lounis, Z. Risk-based maintenance optimization of aging highway bridge decks, In Advances in Engineering Structures, Mechanics $\mathcal{E}$ Construction; Springer: Dordrecht, The Netherlands, 2006; pp. 723-734.

21. Saydam, D.; Frangopol, D.M. Risk-based maintenance optimization of deteriorating bridges. J. Struct. Eng. 2015, 141, 04014120. [CrossRef]

22. Liu, L.; Yang, D.Y.; Frangopol, D.M. Determining target reliability index of structures based on cost optimization and acceptance criteria for fatality risk. ASCE-ASME J. Risk Uncertain. Eng. Syst. Part A Civ. Eng. 2021, 7, 04021013. [CrossRef]

23. Li, L.; Mahmoodian, M.; Li, C.Q.; Robert, D. Effect of corrosion and hydrogen embrittlement on microstructure and mechanical properties of mild steel. Constr. Build. Mater. 2018, 170, 78-90. [CrossRef]

24. Kurtz, N.; Song, J.; Gardoni, P. Seismic reliability analysis of deteriorating representative US West Coast bridge transportation networks. J. Struct. Eng. 2016, 142, C4015010. [CrossRef]

25. Guo, T.; Chen, Z.; Liu, T.; Han, D. Time-dependent reliability of strengthened PSC box-girder bridge using phased and incremental static analyses. Eng. Struct. 2016, 117, 358-371. [CrossRef]

26. Han, Y.; Li, K.; Cai, C.S.; Wang, L.; Xu, G. Fatigue reliability assessment of long-span steel-truss suspension bridges under the combined action of random traffic and wind loads. J. Bridge Eng. 2020, 25, 04020003. [CrossRef]

27. Garbatov, Y.; Soares, C.G.; Parunov, J.; Kodvanj, J. Tensile strength assessment of corroded small scale specimens. Corros. Sci. 2014, 85, 296-303. [CrossRef]

28. Li, L.; Mahmoodian, M. Fatigue life prediction and maintainance management of steel structures subjected to corrosion. Aust. J. Struct. Eng. 2021, 1-14. [CrossRef]

29. Li, C.Q.; Melchers, R.E. Time-dependent reliability analysis of corrosion-induced concrete cracking. ACI Struct. J. 2005, 102, 543.

30. Collings, D. Steel-Concrete Composite Bridges; Thomas Telford: London, UK, 2005.

31. Lee, H.E.; Kim, K.D.; Gil, H.B.; Yi, J.W. Stringer-to-cross beam connections behavior of steel box girder bridge. J. Korean Soc. Steel Constr. 1999, 11, 571

32. Thompson, M.; Eamon, C.; Rais-Rohani, M. Reliability-Based Optimization of FRP Deck Panels. In Proceedings of the 14th AIAA/ASME/AHS Adaptive Structures Conference 7th, Newport, UK, 1-4 May 2006; p. 2157.

33. AS 5100.1; Bridge Design, Part 1: Scope and General Principles. Standards: Sydney, Australia, 2017.

34. Li, C.Q.; Melchers, R. Outcrossings from convex polyhedrons for nonstationary gaussian processes. ASCE J. Eng. Mech. 1993, 119, 2354-2361. [CrossRef]

35. Lisnianski, A.; Frenkel, I.; Ding, Y. Multi-State System Reliability Analysis and Optimization for Engineers and Industrial Managers, Springer Science \& Business Media: Berlin, Germany, 2010.

36. Li, L.; Mahmoodian, M.; Li, C.Q. Prediction of fatigue failure of corrosion affected riveted connections in steel structures. Struct. Infrastruct. Eng. 2020, 16, 1524-1538. [CrossRef]

37. Zhao, Z.; Haldar, A.; Breen, F.L., Jr. Fatigue-reliability evaluation of steel bridges. J. Struct. Eng. 1994, 120, 1608-1623. [CrossRef]

38. Jiang, Q.M.; Kai, S.H.I.; Lan, S.N. Time-Dependent Reliability of Concrete Structure in Chloride Environment. In Proceedings of the 7th International Conference on Energy and Environmental Protection Proceedings, Shenzhen, China, 14-15 July 2018; Elsevier: Shenzhen, China, 2018; Volume 170, pp. 78-83.

39. Zampieri, P.; Curtarello, A.; Pellegrino, C.; Maiorana, E. Fatigue strength of corroded bolted connection. Frat. Ed Integrità Strutt. 2017, 12, 90-96. [CrossRef]

40. Yang, S.I.; Frangopol, D.M.; Kawakami, Y.; Neves, L.C. The use of lifetime functions in the optimization of interventions on existing bridges considering maintenance and failure costs. Reliab. Eng. Syst. Saf. 2006, 91, 698-705. [CrossRef] 
41. Adasooriya, N.; Siriwardane, S. Remaining fatigue life estimation of corroded bridge members. Fatigue Fract. Eng. Mater. Struct. 2014, 37, 603-622. [CrossRef]

42. Tomasz, S. The whole life costing of bridge deck replacement-A case study. In Proceedings of the 6th International Conference on Bridge Maintenance, Safety and Management Proccedings, Lake Maggiore, Italy, 8-12 July 2012.

43. Tserng, H.P.; Chung, C.L. Health assessment and maintenance strategy for bridge management systems: Lessons learned in Taiwan. J. Infrastruct. Syst. 2007, 13, 235-246. [CrossRef]

44. Sarma, K.C.; Adeli, H. Life-cycle cost optimization of steel structures. Int. J. Numer. Methods Eng. 2002, 55, 1451-1462. [CrossRef]

45. Aidoo, J.; Harries, K.A.; Petrou, M.F. Fatigue behavior of carbon fiber reinforced polymer-strengthened reinforced concrete bridge girders. J. Compos. Constr. 2004, 8, 501-509. [CrossRef]

46. Bikul'Chus, G. Chloride removal from reinforced concrete and relevant loss of strength. Prot. Met. 2005, 41, 484-486. [CrossRef] 